\title{
Animalia: the kingdom of signs
}

Pauline Delahaye

Sorbonne Université-Orcid 248809234

When I was offered the role of invited editor for this special issue, I couldn't have been more enthusiastic. Firstly, because it is, of course, always a great honour, especiaIly the first time. Secondly, because I always crave more work and exposure for zoosemiotics, which is still a minor field. Also, lastly, because the very title of this journal has a very deep connection with what has been my job for six years now. Certain researchers are anchored in a very precise field and they are even sometimes the standard bearer, but this is not the case for me. I am studying frontiers, various frontiers; between what is human and what is not, between what is language and what is not, between emotions, between knowledge and belief, between zoology and semiotics.

A frontier is a strange thing: it is where contacts occur, where disciplines split, where we meet, and where we part. We are never completely sure of why it is there, but we need it, especially in science. Frontiers between species are quite arbitrary, for example. Currently, the canon definition is that two groups are different species when they cannot breed between each other and have a fertile offspring, but they are many species challenging this definition-yet we need it to study nature. The frontier between humans and other animals is more disturbing but also very arbitrary. Each time someone tries to find a "Propre de l'Homme," it is sooner or later dismissed. ${ }^{1}$ However, we do need to separate zoosemiotics from anthroposemiotics, just because the methodologies, tools, and subjects are not the same. Maybe, to start this special issue, here is the best definition I can give: zoosemiotics is the semiotics we use to study all species from the animal (Animalia) kingdom which are not ourselves.

Animalia is really the kingdom of signs. Of course, other kingdoms have signs, and sometimes very complex ones, but Animalia, mostly because the beings included in this kingdom can move and eat other beings-and sometimes each other-has pushed this ability to an incredible diversity. Of course, it is not a question here of drawing a fixed limit between this taxon and the others. First of all, because that would be contrary to what I said above about frontiers, and if there is one place where frontiers are arbitrary, it is in the realm of living things. ${ }^{2}$ Second, because that would be absurd; the signs pass from one species to another, from one kingdom to another, without worrying about our categories. Flowers have developed patterns imperceptible to our eyes to attract the insects that pollinate them, while other insects have taken on the appearance of flowers to hunt these same pollinators. As I said above, frontiers are sometimes necessary evils to be able to study a subject. So, let's isolate Animalia for a few papers and see what zoosemiotics can teach us about this tiny but incredibly varied kingdom.

Traditionally, it is admitted that zoosemiotics originated with Jakob von Uexküll and his concept of the Umwelt. When the ethologist asked himself questions about an experience or about the world through the senses of another animal-let's say a tick, to choose a canonical example-he did not yet have at his disposal the tools

1 To be perfectly honest, it is important to admit that there are, indeed, specificities of our species, as with any other species, but the frontiers I am talking about here are of a completely different nature. These "Propre de l'Homme" which were ardently sought after had to be symbolically powerful (altruism, Art, tools, awareness of death and so many others). A simple biological particularity, like the extremely specific position of our occipital hole, would not be satisfying. Silver Rattasepp, for whom I had the pleasure of being a jury member for his doctoral defence, wrote in his thesis that the "Propre de l'Homme" was much more probably measles, but it did not seem to interest anyone.

2 The current pandemic must even remind us that the question "what is life?" has still not been fully answered. Although, according to current taxonomy, a virus is not considered "alive", the fact that everyone, including scientists at their lectures or their explanations to the general public, talk about "killing the virus" or "fragments of dead virus", shows that the current consensus does not suit the idea that we have of life and of what comes under its realm. 
that current zoosemioticians have. He had no access to the main part of chemical exchanges between species, no access to many sounds that are above or below the human hearing abilities, no access to a large variety of visual signs that can only make sense outside of the visible spectrum of the light. The spectrum of zoosemiotics today is larger than at its beginning, and this is good news, the sign of a healthy and fertile field. Consequently, for this special issue, I intended to gather scholars and subjects that represent fairly this large spectrum of themes, this variety of types of signs studied.

At the very beginning of this issue, as a way to remember its origins and the debates that first occurred about the place of the language in zoosemiotics, we will talk about linguistics. The paper "Semiotic Threshold: Animals and People" will propose reflections and suggestions on the way to define language in a way that is useful for semioticians, in general, and zoosemioticians, more specifically. Obviously, the point is not to definitely close a debate that has probably no possible end, but to ask a clear question: what kind of point of view about language will lead us to learn useful things in zoosemiotics and how do we know it is relevant?

The second paper grows at the complete opposite of the spectrum, from a field mostly neglected, precisely because it was a way of communication too far away from human language, the communication through chemical signs, or, as the author calls it "chemosemiosis." But, in an atypical way, the article "Chemosemiosis and Complex Patterned Signals: A Chemosemiotic Hypothesis of Language Evolution" will again lead us to the language area. If zoosemiotics is indeed a discipline dedicated to the study of what is, by definition, foreign to us, this article pushes this aspect to a level still rarely reached: by showing us that the question of language can even be nested in modes of communication which are most closed to us, and for which we are the most ill-equipped.
Two articles, which discuss the same topic from different perspectives, follow. The first one, "Imitation as Mechanism for Mimicry," proposes to study its subject by turning over to the origins of the zoosemiotics and to talk about old theories and their heritage. Born from ethologists like Uexküll or Lorenz, very close to Darwinian theories, zoosemiotics have been at some points in conflict with neo-Darwinian theories, in which important aspects of the original theories were left aside. This article will explain why, on its subject, neo-Darwinianism is not a satisfying and relevant theoretical frame.

The second one, "Metaphors to Survive by: Mimicry as Biometaphors-Embodiment of Sign and Cognition (not only) in Animals?" proposes to study a close subject but introducing new theories and ways to deal with scientific questions. The article introduces the CMT (Cognitive Metaphor Theory) to ask if it could be useful in the context of zoosemiotics and ethology, allowing us to understand differently and to learn new things on the chosen subject.

The very last contribution, to be perfectly honest, is mine. To close this special edition, I wanted to talk a bit about the future that I see in zoosemiotics. I wanted to present a subject, an aspect of our discipline that I believe to be promising and fruitful: the study of interactions between species, and more precisely between humans and the species whose territory they share. A study that aims to be symbolic, emotional, and pragmatic at the same time, because as always, I like to work at the crossroads, at the border. In this sense, zoosemiotics meets the concerns of ecosemiotics, which is good news from my point of view: a discipline that remains isolated in its corner has no chance of prospering, it is by interacting endlessly with the frontiers that knowledge improves. 